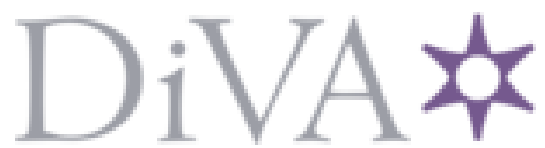

http://www.diva-portal.org

This is the published version of a paper published in Journal of teaching in physical education.

Citation for the original published paper (version of record):

Barker, D., Quennerstedt, M., Johansson, A., Korp, P. (2020)

Physical Education Teachers and Competing Obesity Discourses: An Examination of

Emerging Professional Identities

Journal of teaching in physical education

https://doi.org/10.1123/jtpe.2020-0110

Access to the published version may require subscription.

N.B. When citing this work, cite the original published paper.

Permanent link to this version:

http://urn.kb.se/resolve?urn=urn:nbn:se:oru:diva-88405 


\title{
Physical Education Teachers and Competing Obesity Discourses: An Examination of Emerging Professional Identities
}

\author{
Dean Barker and Mikael Quennerstedt \\ Örebro University \\ Anna Johansson \\ University West \\ Peter Korp \\ University of Gothenburg
}

\begin{abstract}
Aim: To provide insight into how physical education teachers use discursive resources related to obesity to create particular professional identities. Method: Data come from focus group and individual interviews with physical education teachers in Sweden. Discourse theory on teacher identities frame the analysis of the empirical material. Results: Data suggest that teachers in Sweden make use of six distinct but related discursive contributions to produce three professional identities: the caring practitioner, an identity concerned with ensuring all pupils irrespective of size participate in physical education; the activity luminary, an identity that focuses on inspiring pupils toward activity across the lifespan, and; the body rationalist, an identity concerned with challenging unrealistic media discourses and reassuring pupils that they have "normal" bodies. Discussion: The identities appear more inclusive, sensitive, and critical than current physical education literature on obesity suggests, however they also contain elements that are fundamentally unsympathetic to overweight individuals.
\end{abstract}

Keywords: bodies, health, overweight, physical activity

Some years back, Tinning (2015) published a paper examining the academic debate occurring around physical education and the obesity crisis. Building on a discussion already developing in physical education literature (see, e.g., Gard, 2004; Pringle \& Pringle, 2012), Tinning's thesis was that scholars had organized themselves into two camps: one that considered the main mission of physical education to be facilitating better biological health and preventing obesity and one that took a more holistic view of health and considered physical educators' mission to be fundamentally educational. Discussions such as Tinning's (2015) are important for their intent to encourage academics to consider their positions vis-à-vis one of the most contentious issues in the field in recent times (Wrynn, 2011). Of equal importance but receiving far less

(C) 2020 The Authors. Published by Human Kinetics, Inc. This is an Open Access article distributed under the terms of the Creative Commons Attribution-NonCommercial 4.0 International License, CC BY-NC 4.0, which permits the copy and redistribution in any medium or format, provided it is not used for commercial purposes, the original work is properly cited, the new use includes a link to the license, and any changes are indicated. See http://creativecommons.org/licenses/bync/4.0. This license does not cover any third-party material that may appear with permission in the article. For commercial use, permission should be requested from Human Kinetics, Inc., through the Copyright Clearance Center (http://www. copyright.com).

Barker and Quennerstedt are with the School of Health Sciences, Örebro University, Örebro, Sweden. Johansson is with the Division of Social Work and Social Pedagogy, University West, Trollhattan, Sweden. Korp is with the Department of Food and Nutrition, and Sport Science, University of Gothenburg, Gothenburg, Sweden. Barker (dean.barker@oru.se) is corresponding author. scientific attention, are the ways in which physical education teachers position themselves with respect to obesity discourses (Fontana, Furtado, Marston, Mazzardo, \& Gallagher, 2013). Given: (a) teachers' considerable influence on pupils' classroom experiences (Pausé, 2019; Quennerstedt, 2019) and (b) the significance obesity assumes in popular and political discussions of physical education (Gard \& Wright, 2005; Powell, 2016), an understanding of this topic is crucial to understanding contemporary physical education practices. In this paper, we investigate how teachers use obesity discourse to produce professional identities in an interpretive manner. Our interpretations of the claims made and the identities produced contain critical elements. Through critiquing and problematizing existing teacher identities, we propose that new approaches to obesity in physical education are necessary.

\section{Physical Education Teacher Identities and Obesity Discourses}

A great deal has been written about physical education teachers' identities over the years (Hendry, 1975; O'Connor \& MacDonald, 2002) and very little of it has been positive. Sirna, Tinning, and Rossi (2010), for example, suggested that physical educators' behaviors are shaped by marginalizing norms concerning gender, sexuality, and body size. Tinning (2004) proposed that physical education teachers have a history of being depicted as "insensitive to social issues, elitist, sexist, [as] 'pragmatic sceptics' and [as] anti-intellectual" (p. 244). These kinds of categorizations are broad 
and possibly influenced by researchers' propensities to focus on the problematic. Nonetheless, it is worth considering how physical education teachers' identities are connected to body size discourses, especially given that anti-fat bias remains prevalent among preservice physical education teachers (Lynagh, Cliff, \& Morgan, 2015; Varea \& Underwood, 2016).

An important facet of identity made available for physical education teachers by a healthiest discourse (a discourse that equates health with fitness and being slim, Crawford, 1980) is the "exemplary body." Much research has focused on teachers' understandings of health in relation to their own bodies (Sirna et al., 2010; Webb \& Quennerstedt, 2010). Several scholars have pointed out that in-service and preservice physical education teachers tend to value sporty, slim, and able bodies (González-Calvo, Varea, \& Martínez-Álvarez, 2019) and are often committed to displaying these bodies during teaching (Parkinson \& Burrows, 2020; Yager, Gray, Curry, \& McLean, 2020). Indeed, the fit body is seen as pedagogical by nature of the work it achieves as a model to which others can aspire. González-Calvo et al. (2019) summarize this logic, noting that for the preservice teachers in their research, being slim and muscular and being good at traditional sports were necessary "to establish coherence" (p. 161, emphasis added). Teachers' preoccupation with healthy appearances can lead to anxiety, particularly when bodies fail to be sporty, slim, and capable (Webb \& Quennerstedt, 2010).

Alongside the idea of the exemplary body is a second kind of positioning achieved by fat-fighting discourse (Rail, Holmes, \& Murray, 2010). In a "battle" against obesity (Bott \& Mitchell, 2015), physical education teachers are "conscripted" (Powell, 2016, p. 5) and become "crusaders" against fatness (Pringle \& Pringle, 2012, p. 144). Combating a growing enemy, schools and teachers are "the frontline" (Fontana et al., 2013, p. 15). While arguably gaining physical education a degree of status within society, this kind of language is risky because in desperate times, desperate measures may be required (Gard \& Wright, 2005). The crusading physical educator may engage in practices that would not be used during "peace time," and there is a link between fat-fighting language and research findings that point to insensitive and potentially humiliating pedagogies in physical education (Pausé, 2019; Sykes \& McPhail, 2008).

Religious allusions can also be identified in discussions of obesity within physical education research (Schee, 2009). Scholars have pointed out that the teacher is "increasingly seen as a kind of evangelist, such that they must simultaneously homilize and embody health" (Schee \& Gard, 2014, p. 211). When obesity is connected with sloth and gluttony and described as a public health concern in "apocalyptic tones" (Schee \& Gard, 2014, p. 215), the physical education teacher becomes a moral guide comparable to a religious cleric (Halse, 2009; Varea \& Underwood, 2016). Physical education teachers must help others to make good decisions that are both healthy and decent and guide young people to "proper" ways of living. The notion that physical education teachers must "practice what they preach" is recurring in practitioners' reflections on teaching health (Varea, 2018), suggesting an explicit value orientation.

A fourth facet of identity relates to the transmission of educational policy. Gard (2008) proposes rather disparagingly that within obesity discourse, teachers become "nothing more than a conduit for already formed healthy lifestyle messages" (p. 499). He goes on to suggest that "the originators of these messages within government and the fields of medicine and public health neither want nor expect teachers to shape or change these messages on their imagined journey into the minds of children" (Gard, 2008, p. 499). In a similar vein, Schee and Gard (2014) look at the implications of policy documents for teachers, claiming that with an increased focus on public health, teachers have become instruments of policy compliance. Other scholars have also drawn attention to the disciplinary and surveillance-oriented dimension of policy enactment (Wright, Burrows, \& Rich, 2012; Wright \& Halse, 2014). In Schee and Gard's view, teachers now work as regulators and must "ban, encourage and/or monitor [children's bodies and health practices]" (p. 219).

Finally, some scholars have combined a practical orientation with an inclusive language to make recommendations on how to improve overweight children's experiences of physical education. Rukavina and Doolittle (2016), for example, examine how inclusion and positive physical education experiences can be fostered for overweight and obese students. Tingstrom (2015) considers how the needs of overweight students can be addressed in elementary physical education. Within this scholarship, physical educators take on the tasks of determining and meeting the needs of overweight students, creating safe and inclusive learning environments, and understanding barriers to participation (Rukavina, Doolittle, Li, Manson, \& Beale, 2015; Stewart \& Webster, 2018). In this way, obesity discourse produces caring custodian identities.

Whether these five facets are evident in teachers' descriptions of their pedagogical work is unclear. In investigations where teachers have been asked about their responsibilities in relation to young people's health, they have used phrases such as "role models" (Varea, 2018, p. 252; Webb, Quennerstedt, \& Öhman, 2008, p. 364) and "getting students active" (Wrench \& Garrett, 2012, p. 10). Such statements do not indicate evangelical, disciplinary, or overtly policy-related positions. For this reason, the aim of this paper is to provide insight into how teachers use discursive resources related to obesity to create particular professional identities. In the next section, we outline our theoretical approach to discursive resources and identity.

\section{Theoretical Framework: Discursive Contributions and Identity Bids}

Professional identities of teachers have received significant attention from educational researchers (Coldron \& Smith, 1999; Flores \& Day, 2006; Thomas \& Beauchamp, 2011). There is general agreement that teachers' professional identities are closely tied to their engagement, commitment, and actions in and out of the classroom (Renga, Peck, Feliciano-Semidei, Erickson, \& Wu, 2020). In this paper, we take a discursive approach (Biesta, Priestley, \& Robinson, 2017), viewing identities as "an ongoing, dynamic process in which individuals negotiate external and internal expectations" (Cohen, 2010 , p. 473). For analytic purposes, we divide the process of identity negotiation simply into what people communicate and the potential identities that are created by what they communicate. To conceptualize this first aspect, we are going to employ the notion of discursive contributions. To conceptualize the second aspect, we are going to use the notion of identity bids.

To explain what we mean with discursive contribution, we want to enlist the help of Wetherall and Potter (1988). These authors suggest that when people interact, they use existing language blocks to construct explanations and accounts. Examples of language blocks include narratives ("the dog ate my homework"), stereotypical statements ("Paris is beautiful in the spring"), 
or other pieces of language such as metaphors or allusions that carry meaning ("my office is a pigsty"). Key features of blocks are that (a) they are comprised of a restricted range of terms, which are used in a specific stylistic and grammatical fashion, and (b) they are widely recognizable. Although Wetherall and Potter (1988) use the term "interpretive repertoires" (Barker \& Rossi, 2011, p. 139 in the context of physical education), we employ "discursive contribution" to emphasize people's deployment of familiar fragments of language to participate in local conversations and that by using recognizable blocks, speakers contribute to the propagation of cultural stores of meaning.

Discursive contributions have implications for speakers' identities. To frame these consequences, we are going to use the notion of an identity bid (Cohen, 2010). Cohen suggests that the contributions people make during conversations can be thought of as "bids" on particular identities. When, for example, a teacher recounts a story of how she provided extra tuition for a struggling student, she might be seen to be making a bid on a caring teacher identity. We say "might be seen to" because the categorization of identity bids is understood as an interpretive activity generally conducted by researchers. From this perspective, it is appropriate for researchers to provide evidence of interpretations but not to claim that "this was how individuals wanted to be seen." In the conversational context, bids can be either taken up or rejected by listening colleagues (Cohen, 2010), and in this sense, identity bids are relational (Akkerman \& Meijer, 2011).

As suggested, the use of identity bids signals our understanding of identities as flexible. We agree with Hand and Gresalfi's (2015) claim that sense of self is always under negotiation and that people work to produce identities in moment-to-moment interactions (see also Renga et al., 2020). Interaction often involves the introduction of experiences, understandings, and broader discourses into a dialogic space that exists between speaker and listeners (Hand \& Gresalfi, 2015). Rather than being fixed or innate, identities can be thought of as evolving constructions or performances. The identities described in the second half of the paper are thus not meant as descriptions of actual teachers or teacher types but as recognizable positions that teachers assume at different times in different settings.

\section{Method}

The perspective adopted in the current investigation is interpretive in nature (Woods \& Graber, 2016). Our task has been to closely examine an aspect of physical education that has largely escaped attention, namely how teachers use obesity discourses to describe their pedagogical practices. Close examination has involved (a) revealing complexity that might otherwise remain hidden behind general explanations about teachers' work and (b) problematizing and critiquing the identities emerging from our analysis. Importantly, we do not consider our work to be critical in a theoretical sense (Fitzpatrick, 2019), and we are not primarily concerned with power and structural inequality. We are nonetheless concerned with highlighting logical inconsistencies in the data and questioning more generally whether professional identities in physical education need reconsideration.

\section{Research Context}

The context in which the investigation took place is Swedish physical education. In contrast to many other countries, it has been suggested that Swedish physical education is not so much about sport techniques, competition, learning sports, or fitness (Forest, Lenzen, \&
Öhman, 2018). Sport is not considered the most important issue in physical education among teachers, and fitness testing to promote physical activity and healthy lifestyles are uncommon. Instead, Swedish physical education focuses more on trying out different activities in noncompetitive environments, experiencing joy of movement, being physically active, and enhancing social relations (Larsson \& Karlefors, 2015; Larsson \& Quennerstedt, 2016). Since the last curriculum reform in 2011, there has also been a strong focus on assessment and grades, which has put aspects of movement complexity in a variety of activities in the foreground (Janemalm, Barker, \& Quennerstedt, 2020; Svennberg, 2017).

\section{Participants}

The project participants were 24 qualified physical education teachers (11 women and 13 men) who were working in the profession at the time of the interviews. Participants varied in age (average age was 40 years) and professional experience. Twenty of the participants had been teaching physical education for more than 3 years, of whom 14 had been teaching for more than 10 years. The average teaching experience was 11 years. All except one of the teachers worked in urban or suburban contexts in Sweden. Given that teacher subjectivities have been shown to influence pedagogical approaches (Sykes \& McPhail, 2008), our goal was to select a variety of informants with respect to gender, age, and years of experience in the profession. Different recruitment strategies were used. Initially, invitation letters were sent to 22 schools. Eight schools responded, from which four teachers participated. Physical education teachers known to the research team were then contacted and asked to (a) take part in the project and (b) invite colleagues to participate in the project. This combination of convenience and snowball sampling (Gobo, 2004) resulted in the participation of a further 20 teachers.

\section{Data Collection}

Data production occurred through focus group and individual interviews held at either the participants' schools or at the campus of the university coordinating the project. Two focus group interviews with five participants, four focus group interviews with two participants, and six individual interviews were conducted. Interview format was determined by practical factors-focus groups were the researchers' preferred format but finding times that suited multiple participants was not always possible. In total, 12 interviews were conducted with 24 participants. One interview was conducted by the third author; 11 were conducted by the fourth author. All 12 interviews were conducted in Swedish. Interview questions were based on issues emerging from existing physical education scholarship concerning obesity and were used to explore views and assumptions on bodies, health, and weight in the teaching of the school subject. Questions included: What kinds of experiences do you have when you "deal" with bodies that you consider deviate from norms regarding shape and size? Are you able to identify norms and assumptions that result in some bodies being viewed as "deviant" while others are regarded as "normal?" In line with a semistructured approach (Amis, 2005), all participants were provided with the same questions but the interviewer followed up certain responses with probing questions that allowed participants to elaborate and clarify. In general, the individual interviews required more probing questions from the interviewer than the focus group interviews, where participants could respond 
to one another's comments. The semistructured approach contributed to a certain uniformity across responses, a point with consequences for analysis (see below). Participants introduced topics that they believed were relevant to the interview questions such as physical activity trends in society, social media, and the changing room. Interviews lasted for between 30 and $82 \mathrm{~min}$ (average $59 \mathrm{~min})$.

\section{Analytic Procedures}

Interviews were recorded and transcribed verbatim by professional transcriptionists (a total of 343 pages of transcript). Analysis of the transcripts involved three phases. The first phase was guided by two analytic questions based on the investigation's theoretical framework: (a) What discursive contributions do the teachers use in their conversations? and (b) How do these discursive contributions work as bids on certain identities within the physical education community? This phase involved the first and second authors reading the transcripts multiple times, marking significant extracts, and writing reflections in the margins of the transcripts. The process of reading, marking, and notating was conducted individually and was reliant on recognition: specifically our ability to recognize the teachers' statements as contributions or blocks of language with a specific stylistic and grammatical character (Wetherall \& Potter, 1988). This character was either recurring in the data or reflected in the research literature. In the second phase of analysis, the first and second authors compared and contrasted interview excerpts identified in the first phase and decided on (a) appropriate ways to categorize discursive contributions and (b) how the contributions could be understood as identity bids (Cohen, 2010). This phase helped us to clarify, and in some cases justify, decisions about the kinds of claims that could be made with our data and specific theoretical framework. The third and final phase of analysis involved a process of negotiation together with all coauthors. Goodyear, Kerner, and Quennerstedt' (2019) suggestions for a deliberative strategy were used in order to evaluate each step in the research process in terms of quality. In this phase, the discursive contributions and identity bids were discussed in relation to credibility, resonance, significant contribution, and ethical and meaningful coherence regarding presentation of results. In this sense, comprehensive researcher collaboration at all stages of the research process and a high degree of research reflexivity were important ways that trustworthiness of the interpretations was ensured. The results of these phases are presented in the next section.

\section{Findings}

We identified six discursive contributions in the data: (a) adapting activities, (b) being sensitive when it comes to issues of weight and size, (c) focusing on personal characteristics other than weight, (d) getting kids active, (e) modeling active, healthy lifestyles, and (f) challenging societal norms. The first three of these contributions constitute bids on what we term, a caring practitioner identity. The fourth and fifth contributions constitute a bid on an activity luminary identity, and the final contribution constitutes a bid on a body rationalist identity (Figure 1).

\section{The Caring Practitioner}

The caring practitioner identity is concerned with working in studentcentered ways and avoiding exclusive practices. This identity is

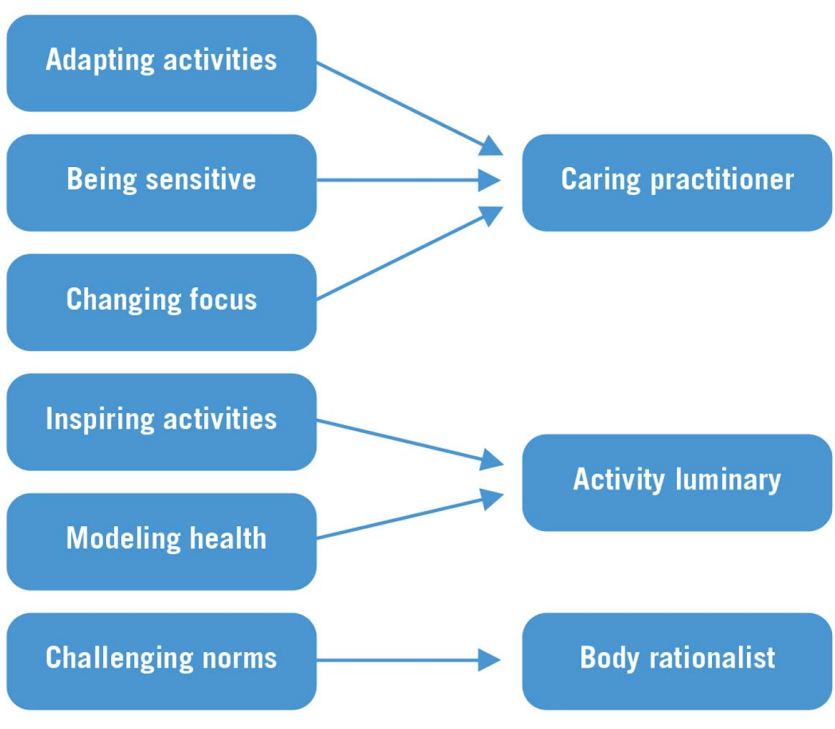

Figure 1 - Identity bids made by discursive contributions.

characterized by a sensitivity to pupils' needs and a willingness to reflect on the affective dimensions of one's teaching. This identity has an applied orientation and is concerned with encouraging overweight pupils to participate. The endeavor is based on the expectation that, if everybody can participate, all pupils will experience benefits of physical education. The identity bid is constituted by three discursive contributions.

Adapting activities so that overweight kids can take part. Many of the teachers contributed to discussions about physical education and obesity with accounts of how they modified activities to enable overweight kids to participate. Common features of this contribution were references to: (a) a provision of parallel activities. This was presented as a measure to avoid overweight kids being observed by peers and potentially feeling ashamed. Participants often referenced gymnastic stations in this contribution. (b) An introduction of different levels of difficulty within one activity. This was presented as a student-centered technique enabling overweight pupils to "choose their own level." Participants described providing easy, medium, and hard alternatives, the suggestion being that overweight kids would choose the easy option. (c) A decreased emphasis on competition and performance. Competitive activities and a focus on performance were often depicted as risky with the potential to "expose" and embarrass pupils.

The students shouldn't watch. Instead you create a high level of activity and individual challenge. Like if we talk about apparatus gymnastics where everyone is at a different level, the pupils work towards their own goals and become very conscious ... of what they are working on, they become really conscious of "Now I'll get better at this and this is what I am practicing." And they really get the opportunity to practice something on an individual basis instead of being exposed while doing stuff that is way beyond their ability (A interview, p. 7)

But the teaching is set up in a way that the students aren't exposed. Instead there are many stations and activity is in full swing, then they don't look at each other. Then they work by themselves and are able to keep on working in their own way. (C interview, p. 15) 
A significant feature of the adaptation contribution was a comparison between current and past physical education practices. Participants frequently contrasted contemporary lessons with traditional physical education, in which "everyone waited in a line watching one person perform." Important here is a strong assertion that as a group, physical education teachers in Sweden have become more inclusive when it comes to students' size.

Being sensitive when it comes to talking about weight and size. A second discursive contribution employed as a bid on the caring practitioner identity posited weight and body size as "an extremely sensitive topic." This contribution comprised small narratives in which pupils' weight became a salient issue. One teacher, for example, described a tag game in which primary-aged pupils needed to carry their peers. The game ended in tears for one pupil who felt that she was too heavy to be lifted. Participants claimed more generally that teachers need to take care when discussing body size.

Yeah, today these things are very sensitive. I can imagine it being much tougher earlier. Like when you divided them, you just "Bang, bang, bang." Head-on . . . . But today I like, very rarely talk about weight. Because yeah, it is supersensitive. (G interview, p. 27)

"Sensitivity" was a recurrent term in this contribution, often prefaced with an intensifier such as "super" or "extremely." "Extreme sensitivity" was predicated on two risks. The first concerned the potential for pupils to experience shame about their bodies. The second was that by raising the issue of weight, teachers would inadvertently lead pupils to attempt losing weight, which could, in turn, lead to eating disorders. Indeed, food and weight were often discussed together as a sensitive topic. Also noteworthy is that some teachers mentioned adolescence as a "particularly sensitive age." Pupils were described as having mutable and unfamiliar bodies while at the same time having a heightened awareness of their bodies in relation to others.

Changing focus and avoiding weight. The third contribution used by teachers to bid on the caring practitioner identity involved the assertion that students' weight did not play a major role in physical education. Often this contribution was expressed as an avowal, containing extremized language.

So we try to remove focus from performance and we never talk body weight, we never talk about how one looks. (B interview, p. 3)

This contribution typically developed in two overlapping subcontributions. First, the teachers proposed that it does not really matter what size the pupils are as long as they have the right attitude.

A student with a normal body is for me a student who arrives content, happy and rested. I don't think that much about the body size. And then they should have a desire to participate. Be hungry like, "OK now, what are we going to do today?" ... and I am looking more at how the whole student .... Not the shape, no (B interview, p. 5)

In addition, the teachers claimed that all pupils have different strengths and weaknesses. According to this logic, given the variety of physical and psychological characteristics found in any class, any disadvantage ensuing from one's weight will be evened out. This assertion was often couched in a naturalizing, liberal language in which pupils had innate abilities and it was up to pupils to "make the most out of" these abilities. Specializing and maximizing one's potential was put forward as an essential lesson outside of school and was connected to finding a suitable form of active recreation.

So in this sense you need to find a wide variety of activities for them right from when they are really young so that they are all able to find something that suits them. And yeah, an environment in which it is ok not to do everything but like, you do what you want, what you feel "this is what I want to focus on." (D interview, p. 3)

Specialization in school, however, was portrayed quite differently because receiving a high grade required pupils to be good across the board. When grading was discussed further, many of the teachers suggested that overweight pupils will not be able to achieve the higher grades in physical education.

Interviewer: Is a certain body required to be a "good" student in health and physical education?

Respondent: No, you can get quite far. Rather, you can say that it is advantageous to have a good physique. It does help you to reach the purely physical goals. And an A is difficult if your body is working against you. That's how I think. Since speed is required. ... If it takes a very long time to run from $\mathrm{A}$ to $\mathrm{B}$ on a ground, then you have missed your chance. You have not become playable or have not come forward. ... Then it becomes difficult for you to adapt your movements . . . . And if you are heavy and can't do stuff in gymnastics or you don't manage to ... you only manage a little bit of rope jumping and then you need to sit down. In other words, you will have difficulty to train yourself and difficulty to show .... It is manageable but it also throws a spanner in the works. (E interview, p. 9)

In an important sense, there were tensions between ignoring students' size and assessment demands, illustrated in the above extract, by having one's body against oneself and one's weight throwing a spanner in the works (translated from "det sätter käppar i hjulen" which literally means "to put a stick in the wheels"). In some instances, teachers added mitigating comments such as, "one does not have to be the world's best football player to be good at physical education," possibly to deflect possible criticism that they were expressing biologically deterministic views of assessment. Nonetheless, the idea that elite athletes might not achieve high grades in physical education did nothing to change the assertion that overweight pupils cannot achieve high grades.

\section{The Activity Luminary}

The activity luminary identity was concerned with inspiring activity and modeling health. The luminary identity grants physical education teachers' bodies symbolic value, making them work as both proof of the healthiest relation between exercise and health (Crawford, 1980) and standards to which others should aspire (cf. González-Calvo et al., 2019; Webb \& Quennerstedt, 2010). This identity is concerned with showing pupils the "right way of living," and while explicit religious allusions noted by some scholars (Halse, 2009; Schee \& Gard, 2014) were uncommon, an ambition to inculcate pupils with an appreciation of an active lifestyle is at the center of this identity. Bids were made on this identity through two discursive contributions: inspiring kids to be active and modeling active, healthy lifestyles. 
Getting kids active in the long term. This discursive contribution concerned physical training and "getting kids active." The contribution was constructed not as much as "activating pupils for health benefits here and now"-although some participants did assert that lessons would have immediate biological benefits—but instead as "inspiring pupils to be active in the future."

It doesn't matter how many classes of physical education we have per week if we are not able to create an interest in continuing the training after school hours. (F interview, p. 1)

Indeed, persuasion was an undercurrent in the "getting kids active" contribution and teaching came to be described as "stimulating" or "turning kids on to" physical activity. Several teachers added that getting active was not about doing elite sport; rather it was about being able to "handle the everyday." The idea of the "everyday" strongly pervaded the teachers' explanations of health, although the exact demands of "the everyday" remained implicit and unspecified.

A central feature of the "getting kids active" contribution was a claim that young people are becoming less active. Participants either commented anecdotally, recounting stories of particularly inactive pupils, or they generalized, stating that decreasing physical activity was a fact of modern life.

When I began here at middle school ... then it was eight out of ten that were in some sort of club .... Now it feels like it is the opposite. Now two out of ten are involved. (C interview, p. 9)

This perceived trend provided a strong rationale for physical education teachers to inspire pupils to physical activity. In this contribution, promoting health is about strengthening resources for managing everyday life rather than burning calories here and now.

Modeling active, healthy lifestyles. A bid on the activity luminary identity could also be discerned in teachers' comments about the place of their own bodies in their pedagogical approaches. When asked about role modeling, two related subcontributions were employed. On the one hand, participants asserted that modeling healthy lifestyles by having trim, fit-looking bodies is an important part of teaching physical education. "Believability" was a recurring term in these accounts, with teachers claiming that pupils were unlikely to take an overweight physical education teacher seriously. Weight, motoric capability, and motivation to be healthy were repeatedly elided so that "an overweight teacher would have neither the skill nor the enthusiasm to teach physical education effectively."

Can you live in an unhealthy way? Yeah, you can. But you'll have no credibility left. Can you be ... can you be an alcoholic as a teacher? Yeah, but you will lose your credibility. If $\mathrm{I}$ as a PE teacher am standing outside and having a smoke, then it doesn't matter if I talk about health because the students will be like "But you smoke." ... And equally I would say that a teacher in health and physical education who is overweight would have a problem with credibility ... . (F interview, p. 19)

On the other hand, it was possible to contribute by saying that overweight physical educators can be role models with a caveat. For example, a physical educator can be overweight if he is getting older, or if she can still demonstrate skills. In fact, body control was pivotal and if a teacher could still move skillfully, neither age nor weight were problematic.

I would say that yes, if you master body control and feel secure enough in yourself not to be uncomfortable in showing certain things for the students ... . You can be big as a teacher in physical education, but it might put a spanner in the works. (E interview, pp. 22-27)

Several teachers went so far as to say that it might be helpful to have more overweight physical education teachers. At the same time, they also suggested that there would be limits to what is acceptable and that they would not feel particularly comfortable if they were overweight themselves.

\section{The Body Rationalist}

The final discursive contribution constituted a bid on what we have termed "the body rationalist" identity. Key in this identity is an aspiration to protect people from irrational cultural messages about bodies (for similar positioning, Varea, 2018). For the body rationalist, manipulative messages lead to "unhealthy" body dissatisfaction. The body rationalist identity involves attempts to sensitize young people to what is being done with, and to bodies in the media and draw attention to techniques that are used to condition people into thinking that improbable bodies are normal, desirable, and attainable.

Challenging societal norms so that kids don't feel bad about their bodies. A bid on a body rationalist identity was made through assertions of challenging societal norms with the tacit assumption being that this would help young people feel satisfied with their bodies and deter them from unhealthy practices. Almost all of the participants suggested that young people are exposed to unrealistic "messages" about bodies through media and social media and stressed that the messages placed young people under considerable pressure. Within this contribution, teachers described how they attempted to expose deceptions within the media and furnish pupils with realistic ideas about "normal" bodies and health. Often cited strategies were, for example, comparing beauty ideals from different eras to illustrate their arbitrariness and discussing graphics editing techniques that allowed body images to be altered.

Then I did this too with Justin Bieber. Here he has a padding, but not there. And so we looked at this girl ... I actually found. This is what she looks like, but then they have retouched her. (B interview, pp. 4-5)

A number of teachers suggested that their pupils were typically quite savvy when it came to the modification of celebrity images, however awareness did not necessarily amount to disapproval. In fact, in the following commentary the teacher couples young people's familiarity with photo enhancing techniques with the pupils' own use of such techniques with social media.

I think they are extremely aware of how bodies are photoshopped today in the media, and if you are a little bit pale and have these rings around your eyes, which is human, they are removed. And if you have pimples like this, they are removed. And a little extra flesh around the waist, they remove it. They are really aware of this. And I have talked about how they and others, how they clean up their Instagram feeds. Since ... "Yeah, I posted it yesterday but I only got 20 likes and then I removed it because I like, want 100 likes to keep it in my feed." (I interview, p. 21) 
Corporeal artifice in need of challenging was not limited to image modification. Several teachers bid on a body rationalist identity through reference to anabolic steroids. In this case, pupils were not portrayed as particularly knowledgeable and teachers frequently described a need to alert pupils to the dangers of using anabolic steroids.

Because that's how they consider it, that if I take anabolic steroids, I get big muscles. "Yes, but what do you think happens apart from that?" And then like ... they haven't thought of the consequences, so once again this is a pretty serious issue that scares some students. Some students, they just brush it off, and go from class without thinking about it again ... . But this is an important part in this, regarding the aspect of health, to see the downside of the glamour. Because anyway, that's how it is, the media only shows the glamour. (A interview, p. 30)

Neither dieting nor cosmetic surgery featured in this discursive contribution, an interesting omission given the emphasis placed on critiquing corporeal artifice and glamour. A potential explanation is that teachers feared inadvertently encouraging pupils to engage in such practices, an explanation consistent with the "being sensitive" contribution described above. Also noteworthy is that this contribution regularly intersected with comments about a general stress on young people. Commentary often involved claims that pupils needed to be steered away from trying to be perfect and that investment in unrealistic body ideals was symptomatic of wider social trends related to performance and achievement.

\section{Discussion}

In this section, we discuss each of the three identities in turn. Our ambition is to locate the identities within the literature introduced earlier in the paper and highlight potential issues or problems with each identity. In the final section, we then raise some broader points for consideration that relate to all three identities.

The caring practitioner identity is concerned with avoiding exclusive practices. As such, the identity is possibly-but not necessarily - at odds with descriptions of a humiliating, stigmatizing physical education (Pausé, 2019; Sykes \& McPhail, 2008) as well as general portrayals of physical educators as insensitive and as inclined to engage in anti-fat practices (Lynagh et al., 2015; Sirna et al., 2010). The identity is, on the other hand, closely aligned with the inclusive role advocated in recent, practicallyoriented scholarship (Rukavina et al., 2015; Tingstrom, 2015).

While the caring practitioner identity may match recent recommendations (Rukavina \& Doolittle, 2016), two issues warrant consideration. First, the inclusive practitioner's concern with focusing on the "here and now," avoiding "shameful situations," and often circumventing the issue of weight all together, does little to address why people might feel shame in the first place. Without confronting the mechanisms of shame-why it is connected with overweight bodies and why it becomes pronounced in certain situations, for examplechanging existing experiences and practices in physical education would appear difficult. Borrowing from critiques of color blindness (Flintoff \& Dowling, 2019), we might say that the caring practitioner identity involves a disregard for connections between sociohistorical context and affective experience, and inattention to how body discourses influence the educational encounters of pupils. The caring practitioner engages in other words, in a kind of "weight blindness."

Related, the student-centeredness of the caring practitioner is often based on an ability hierarchy that positions overweight pupils at the bottom (cf. discussions of ableism and "the illegitimate attributions of abilities in ... sport pedagogic context[s]"; Giese \& Ruin, 2018, p. 155). Overweight pupils should participate, and also want to participate at their own level, but this level of ability is presumed to be the lowest in relation to a taken-for-granted content. Indeed, embedded within the teachers' conception of physical education as a multidimensional subject is the logic that overweight pupils will inevitably achieve lower grades. In this sense, the caring practitioner identity is unlikely to allow overweight pupils to experience their bodies as publically or officially successful.

The activity luminary identity is concerned with inspiring activity and modeling health. This professional identity can be detected in some physical education scholarship (Varea \& Underwood, 2016); although, we would suggest that there are at least two distinguishing characteristics. First, the luminary position emerging from our data is not concerned with producing immediate physiological health benefits during lessons as "fat-fighting" physical educators might (Bott \& Mitchell, 2015; Pringle \& Pringle, 2012). Rather it is about instilling a physically active disposition. In the sense that the luminary attempts to impress values upon pupils, this identity has similarities to the religious cleric (Schee \& Gard, 2014; Halse, 2009), even if explicit religious allusions did not feature in the teachers' comments. Second, the luminary identity gains meaning in relation to increasing sedentariness rather than increasing obesity rates (Gard, 2004). From the luminary position, overweight bodies are among many "problematically inactive" bodies. It is not necessarily the size of the pupils that matters but their (in)capacity or (un)willingness to take part in physical activities.

This second point can be related to the luminary's stance with respect to overweight physical education teachers and extends our thinking on the implicit connection between ability and weight introduced above. While some teachers were open to the possibility of overweight individuals working as physical educators, they also suggested that (a) there would be limits to what is acceptable and (b) overweight teachers would not necessarily have the motoric requisites for inspiring pupils to lifelong physical activity (cf. González-Calvo et al., 2019; Parkinson \& Burrows, 2020). In this manner, the identity contained a tempered expression of fat bias that reflected stereotypical norms about motoric ability and fatness (Fontana et al., 2013; Lynagh et al., 2015), and a distancing from overweight as a negative social marker.

Finally, the body rationalist identity is concerned with protecting young people from unrealistic cultural messages about bodies. At the core of this identity is a concern for the psychological well-being of pupils. Unlike the two former identities, the body rationalist position is constituted through discursive reference to the cultural and the psychological rather than the physical: the problem lies not in the materiality of bodies that "don't fit" but in a potentially harmful social environment.

An attempt to emancipate pupils from oppressive social ideology is in line with a critical pedagogical approach (Fitzpatrick, 2019). The attempt signals a departure from traditional views of physical education teachers as "insensitive to social issues ... , and [as] anti-intellectual" (Tinning, 2004, p. 244). At the same time, by locating the obesity problem in the media and young people's use of social media, the body rationalist ignores any role physical education might have in reproducing anti-fat norms. By focusing on the cultural milieu, the school subject of physical education escapes attention, becoming a safe vantage point from which dangerous social practices can be discussed and problematized. The irony is that despite claims of inclusion and sensitivity, physical education comprises part of this dangerous environment. Even while claiming 
to include pupils of all sizes and inspire pupils to physical activity across the lifespan, the caring practitioner and the activity luminary positions reproduce norms that the rationalist seeks to critique.

\section{Closing Remarks}

This paper has provided insights into the discursive resources related to obesity that are implicated in the production of particular professional identities in school physical education. We have shown how six distinct but related discursive contributions can be used to produce three professional identities: the caring practitioner, an identity concerned with ensuring all pupils irrespective of size are included in physical education; the activity luminary, an identity that focuses on inspiring pupils toward activity across the lifespan; and the body rationalist, an identity concerned with challenging unrealistic body ideals.

In some ways, the identities appear to be more inclusive, more sensitive, and more critical than current physical education literature on obesity suggests. Our interpretation has indicated, however, that the identities contain elements that are fundamentally unsympathetic to overweight individuals. These elements help to explain why despite altruistic intentions, physical education can become an unfriendly place for fat children. To our minds, the identities presented are not duplicitous; teachers-at least those in our investigation - do want to include children of all sizes, avoid shame and embarrassment, and protect children from harmful messages about bodies. It is just that some of the means that they describe to achieve their objectives counteract those same objectives. To remedy the situation, we would argue that pre and in-service teachers and teacher educators need to: (a) reflect on current practices and (b) develop new pedagogical practices.

With reflection on current practices, we suggest that physical educators begin with developing a thorough understanding of anti-fat bias, including what it means and how it takes place in physical education. This would involve discussions of anti-fat bias, as it is presented in physical education scholarship but also as it concerns the people around them. We could imagine that conversations with adults who were overweight during schooling about their experiences in physical education would provide a useful way for physical educators to start thinking about unintended effects of the school subject on pupils. Reflection would also necessarily involve a close examination of one's own practices. Examination could be done through observations where a critical friend sensitized to fat issues observes lessons and records incidents that emerge as relevant. Physical educators could also keep reflective diaries that are structured with particular questions or topics related to weight and pupil experiences. Such diaries could provide useful stimulus for group reflection. Reflection on current practices could further involve asking pupils to provide written accounts on aspects of physical education concerning, for example, what they enjoy and do not enjoy about participation in the school subject. Writing could be done following certain activities and pupils could be invited to comment on specific aspects of physical education such as competition or grading. This would need to be done in a trusting environment where pupils feel that they can express themselves.

On the basis of reflection on current practices, new practices can be developed. Without oversimplifying the situation, the three identities presented in this paper could provide useful starting points. Teachers want to care for pupils of all sizes in physical education. They want to inspire all young people when it comes to being physically active. And they want to help pupils to become critical when it comes to issues related to bodies and body size. There are surely different ways to realize these objectives but we can imagine a physical education that approaches these objectives in a selfcritical, but not overly serious, way. In our thinking, physical educators might care, inspire, and critique playfully, where the institutionalized views and dispositions of physical education are open to question and evaluation. The task of teaching might take on a provocative aspect that involves thinking paradoxically (Kumashiro, 2015) about bodies, physical activity and health. Rather than teach that "this is how we should understand bodies" or "this is what (able) bodies can do," physical educators might ask pupils to question their understandings of bodies and ask them to develop unconventional or alternative understandings. By engaging in these types of activities, teachers might invite pupils to question existing power relations that concern shape and size but also gender, ability, and ethnicity, for example.

This has been a rather truncated consideration of implications but space limitations do not permit more. We would add that creating new pedagogical practices requires an understanding of how cultural context, corporeality, and affective experiences are necessarily connected. For us, it is crucial that preservice teachers have this understanding, a point with relevance to physical education teacher educators. Two final comments are necessary. First, it may be that physical educators will not be receptive to the idea of reflection and change. Given the teachers in this investigation typically indicated that they were already addressing the issue of obesity and that problems lay in the past, problematizing professional identities as they relate to obesity discourse may be met with indignation or defensiveness. In this eventuality, we would suggest that logical inconsistencies between claiming to use caring, inspiring, and rational pedagogies and actually teaching in caring, inspiring, and rational ways is particularly important. Second, as noted, the teachers in this investigation work in a specific cultural context. The identities presented in this paper are in all likelihood the result of obesity discourses being refracted through a particular physical education culture in Sweden that places emphasis on trying out different activities, experiencing joy of movement, being active, and enhancing social relations. Nonetheless, we hope that researchers and practitioners working in different cultural contexts can find value in the interpretations provided here. We trust that, even if the identities identified in this paper do not map exactly onto identities produced in other contexts, consideration of the issues raised can lead to more caring, more inspiring, and more critical physical education practices.

\section{References}

Akkerman, S.F., \& Meijer, P.C. (2011). A dialogical approach to conceptualizing teacher identity. Teaching and Teacher Education, 27(2), 308-319. doi:10.1016/j.tate.2010.08.013

Amis, J. (2005). Interviewing for case study research. In D.L. Andrews, D.S. Mason, \& M.L. Silk (Eds.), Qualitative methods in sports studies (pp. 104-138). Oxford: Berg.

Barker, D.M., \& Rossi, A. (2011). Understanding teachers: The potential and possibility of discourse analysis. Sport, Education and Society, 16(2), 139-158. doi:10.1080/13573322.2011.540421

Biesta, G., Priestley, M., \& Robinson, S. (2017). Talking about education: Exploring the significance of teachers' talk for teacher agency. Journal of Curriculum Studies, 49(1), 38-54. doi:10.1080/ 00220272.2016 .1205143

Bott, T.S., \& Mitchell, M. (2015). Battling obesity with quality elementary physical education: From exposure to competence. Journal of 
Physical Education, Recreation and Dance, 86(6), 24-28. doi:10. 1080/07303084.2015.1053637

Cohen, J.L. (2010). Getting recognised: Teachers negotiating professional identities as learners through talk. Teaching and Teacher Education, 26(3), 473-481. doi:10.1016/j.tate.2009.06.005

Coldron, J., \& Smith, R. (1999). Active location in teachers' construction of their professional identities. Journal of Curriculum Studies, 31(6), 711-726. doi:10.1080/002202799182954

Crawford, R. (1980). Healthism and the medicalization of everyday life. International Journal of Health Services, 10(3), 365-388. PubMed ID: 7419309 doi:10.2190/3H2H-3XJN-3KAY-G9NY

Fitzpatrick, K. (2019). What happened to critical pedagogy in physical education? An analysis of key critical work in the field. European Physical Education Review, 25(4), 1128-1145. doi:10.1177/13563 36X18796530

Flintoff, A., \& Dowling, F. (2019). 'I just treat them all the same, really': Teachers, whiteness and (anti) racism in physical education. Sport, Education and Society, 24(2), 121-133. doi:10.1080/13573322. 2017.1332583

Flores, M.A., \& Day, C. (2006). Contexts which shape and reshape new teachers' identities: A multi-perspective study. Teaching and Teacher Education, 22(2), 219-232. doi:10.1016/j.tate.2005.09.002

Fontana, F.E., Furtado, O., Marston, R., Mazzardo, O., \& Gallagher, J. (2013). Anti-fat bias among physical education teachers and majors. Physical Educator, 70(1), 15-31.

Forest, E., Lenzen, B., \& Öhman, M. (2018). Teaching traditions in physical education in France, Switzerland and Sweden: A special focus on official curricula for gymnastics and fitness training. European Educational Research Journal, 17(1), 71-90. doi:10.1177/ 1474904117708889

Gard, M. (2004). An elephant in the room and a bridge too far, or physical education and the 'obesity epidemic'. In J. Evans, B. Davies, \& J. Wright (Eds.), Body knowledge and control: Studies in the sociology of physical education and health (pp. 545-549). London: Routledge.

Gard, M. (2008). Producing little decision makers and goal setters in the age of the obesity crisis. Quest, 60(4), 488-502. doi:10.1080/ 00336297.2008.10483594

Gard, M., \& Wright, J. (2005). The obesity epidemic: Science, morality, and ideology. London: Routledge.

Giese, M., \& Ruin, S. (2018). Forgotten bodies-An examination of physical education from the perspective of ableism. Sport in Society, 21(1), 152-165. doi:10.1080/17430437.2016.1225857

Gobo, G. (2004). Sampling, representativeness and generalizability. In C. Seale, G. Gobo, J. Gubrium, \& D. Silverman (Eds.), Qualitative research practice (pp. 405-426). London: Sage.

González-Calvo, G., Varea, V., \& Martínez-Álvarez, L. (2019). Health and body tensions and expectations for pre-service physical education teachers in Spain. Sport, Education and Society, 24(2), 158-167. doi:10.1080/13573322.2017.1331426

Goodyear, V.A., Kerner, C., \& Quennerstedt, M. (2019). Young people's uses of wearable healthy lifestyle technologies: Surveillance, selfsurveillance and resistance. Sport, Education and Society, 24(3), 212-225. doi:10.1080/13573322.2017.1375907

Halse, C. (2009). Bio-citizenship: Virtue discourses and the creation of the biocitizen. In J. Wright\& V. Harwood (Eds.), Governing bodies: Biopolitics and the 'obesity epidemic' (pp. 45-59). New York: Routledge.

Hand, V., \& Gresalfi, M. (2015). The joint accomplishment of identity. Educational Psychologist, 50(3), 190-203. doi:10.1080/00461520. 2015.1075401

Hendry, L.B. (1975). Survival in a marginal role: The professional identity of the physical education teacher. The British Journal of Sociology, 26(4), 465-476. doi:10.2307/589823
Janemalm, L., Barker, D., \& Quennerstedt, M. (2020). Transformation of complex movements from policy to practice-A discourse analysis of Swedish physical education teachers' concepts of moving. Physical Education and Sport Pedagogy, 25(4), 410-422. doi:10.1080/ 17408989.2020.1727869

Kumashiro, K.K. (2015). Against common sense: Teaching and learning toward social justice. London, UK: Routledge.

Larsson, H., \& Karlefors, I. (2015). Physical education cultures in Sweden: fitness, sports, dancing... learning? Sport, Education and Society, 20(5), 573-587. doi:10.1080/13573322.2014.979143

Larsson, H., \& Quennerstedt, M. (2016). Same, same but different: (Re) understanding the place of context in physical education practice. Recherches \& Éducations, 15, 69-86.

Lynagh, M., Cliff, K., \& Morgan, P. (2015). Attitudes and beliefs of nonspecialist and specialist trainee health and physical education teachers toward obese children: Evidence for 'anti-fat' bias. Journal of School Health, 85(9), 595-603. PubMed ID: 26201756 doi:10. 1111/josh. 12287

O'Connor, A., \& MacDonald, D. (2002). Up close and personal on physical education teachers' identity: Is conflict an issue? Sport, Education and Society, 7(1), 37-54.

Parkinson, S., \& Burrows, A. (2020). Physical educator and/or health promoter? Constructing 'healthiness' and embodying a 'healthy role model' in secondary school physical education. Sport, Education and Society, 25(4), 365-377. doi:10.1080/13573322.2019.1613635

Pausé, C. (2019). (Can we) get together? Fat kids and physical education. Health Education Journal, 78(6), 662-669. doi:10.1177/001789691 9846182

Powell, D. (2016). Schools and the 'war against obesity.' New Zealand Physical Educator, 49(3), 4-5.

Pringle, R., \& Pringle, D. (2012). Competing obesity discourses and critical challenges for health and physical educators. Sport, Education and Society, 17(2), 143-161. doi:10.1080/13573322.2011.607947

Quennerstedt, M. (2019). Physical education and the art of teaching: Transformative learning and teaching in physical education and sports pedagogy. Sport, Education and Society, 24(6), 611-623. doi:10.1080/13573322.2019.1574731

Rail, G., Holmes, D., \& Murray, S.J. (2010). The politics of evidence on 'domestic terrorists': Obesity discourses and their effects. Social Theory \& Health, 8(3), 259-279. doi:10.1057/sth.2009.10

Renga, I.P., Peck, F.A., Feliciano-Semidei, R., Erickson, D., \& Wu, K. (2020). Doing math and talking school: Professional talk as producing hybridity in teacher identity and community. Linguistics and Education, 55, 100766. doi:10.1016/j.linged.2019.100766

Rukavina, P.B., \& Doolittle, S.A. (2016). Fostering inclusion and positive physical education experiences for overweight and obese students. Journal of Physical Education, Recreation \& Dance, 87(4), 36-45. doi:10.1080/07303084.2016.1141730

Rukavina, P.B., Doolittle, S., Li, W., Manson, M., \& Beale, A. (2015). Middle school teachers' strategies for including overweight students in skill and fitness instruction. Journal of Teaching in Physical Education, 34(1), 93-118. doi:10.1123/jtpe.2013-0152

Schee, C. (2009). Confessions of the 'Unhealthy'-Eating chocolate in the halls and smoking behind the bus garage: Teachers as health missionaries. British Journal of Sociology of Education, 30(4), 407-419. doi:10.1080/01425690902954596

Schee, C., \& Gard, M. (2014). Healthy, happy and ready to teach, or why kids can't learn from fat teachers: The discursive politics of school reform and teacher health. Critical Public Health, 24(2), 210-225. doi:10.1080/09581596.2013.828152

Sirna, K., Tinning, R., \& Rossi, T. (2010). Social processes of health and physical education teachers' identity formation: Reproducing and 
changing culture. British Journal of Sociology of Education, 31(1), 71-84. doi:10.1080/01425690903385501

Stewart, G.L., \& Webster, C.A. (2018). The role of physical educators in addressing the needs of students who are overweight and obese. Journal of Physical Education, Recreation and Dance, 89(1), 30-34. doi:10.1080/07303084.2017.1390505

Svennberg, L. (2017). Swedish PE teachers' understandings of legitimate movement in a criterion-referenced grading system. Physical Education and Sport Pedagogy, 22(3), 257-269. doi:10.1080/17408989. 2016.1176132

Sykes, H., \& McPhail, D. (2008). Unbearable lessons: Contesting fat phobia in physical education. Sociology of Sport Journal, 25(1), 66-96. doi:10.1123/ssj.25.1.66

Thomas, L., \& Beauchamp, C. (2011). Understanding new teachers' professional identities through metaphor. Teaching and Teacher Education, 27(4), 762-769. doi:10.1016/j.tate.2010.12.007

Tingstrom, C.A. (2015). Addressing the needs of overweight students in elementary physical education: Creating an environment of care and success. Strategies, 28(1), 8-12. doi:10.1080/08924562.2014.980875

Tinning, R. (2004). Rethinking the preparation of HPE teachers: Ruminations on knowledge, identity, and ways of thinking. Asia-Pacific Journal of Teacher Education, 32(3), 241-253.

Tinning, R. (2015). 'I don't read fiction': Academic discourse and the relationship between health and physical education. Sport, Education and Society, 20(6), 710-721. doi:10.1080/13573322.2013. 798638

Varea, V. (2018). Mixed messages: Pre-service health and physical education teachers' understandings of health and the body and the expectations of the Australian curriculum. Sport, Education and Society, 23(3), 244-256. doi:10.1080/13573322.2016.1179182

Varea, V., \& Underwood, M. (2016). 'You are just an idiot for not doing any physical activity right now': Pre-service health and physical education teachers' constructions of fatness. European Physical Education Review, 22(4), 465-478. doi:10.1177/1356336X15617446
Webb, L., \& Quennerstedt, M. (2010). Risky bodies: Health surveillance and teachers' embodiment of health. International Journal of Qualitative Studies in Education, 23(7), 785-802. doi:10.1080/09518398. 2010.529471

Webb, L., Quennerstedt, M., \& Öhman, M. (2008). Healthy bodies: Construction of the body and health in physical education. Sport, Education and Society, 13(4), 353-372. doi:10.1080/13573320 802444960

Wetherall, M., \& Potter, J. (1988). Discourse analysis and the identification of interpretative repertoires. In C. Antaki (Ed.), Analysing everyday explanation: A casebook of methods (pp. 168-183). London: Sage.

Woods, A.M., \& Graber, K.C. (2016). Interpretive and critical research: A view through a qualitative lens. In K. Armour, A. Chen, C. Ennis, A. Garn, E. Mauerberg-deCastro, D. Penney, S. Silverman, M. Solomon, \& R. Tinning (Eds.), Routledge handbook of physical education pedagogies (pp. 21-33). London: Routledge.

Wrench, A., \& Garrett, R. (2012). Identity work: Stories told in learning to teach physical education. Sport, Education and Society, 17(1), 1-19. doi:10.1080/13573322.2011.607909

Wright, J., Burrows, L., \& Rich, E. (2012). Health imperatives in primary schools across three countries: Intersections of class, culture and subjectivity. Discourse: Studies in the Cultural Politics of Education, 33(5), 673-691.

Wright, J., \& Halse, C. (2014). The healthy child citizen: Biopedagogies and web-based health promotion. British Journal of Sociology of Education, 35(6), 837-855. doi:10.1080/01425692.2013. 800446

Wrynn, A.M. (2011). Beyond the standard measures: Physical education's impact on the dialogue about obesity in the 20th century. Quest, 63(2), 161-178. doi:10.1080/00336297.2011.10483674

Yager, Z., Gray, T., Curry, C., \& McLean, S.A. (2020). Pre-service teachers' gendered attitudes towards role modelling in health and physical education. Physical Education and Sport Pedagogy, 25(1), 67-78. doi:10.1080/17408989.2019.1688774 